\title{
Article
}

\section{Investigation of polyviologens as oxygen indicators in food packaging}

Roberts, L, Lines, R, Reddy, Subrayal M and Hay, J

Available at http://clok.uclan.ac.uk/13676/

Roberts, L, Lines, R, Reddy, Subrayal M ORCID: 0000-0002-7362-184X and Hay, J (2010) Investigation of polyviologens as oxygen indicators in food packaging. Sensors and Actuators B: Chemical, 152 (1). 63 - 67.

It is advisable to refer to the publisher's version if you intend to cite from the work. http://dx.doi.org/10.1016/j.snb.2010.09.047

For more information about UCLan's research in this area go to http://www.uclan.ac.uk/researchgroups/ and search for < name of research Group>.

For information about Research generally at UCLan please go to http://www.uclan.ac.uk/research/

All outputs in CLoK are protected by Intellectual Property Rights law, including Copyright law. Copyright, IPR and Moral Rights for the works on this site are retained by the individual authors and/or other copyright owners. Terms and conditions for use of this material are defined in the policies page.

\section{CLoK}

Central Lancashire online Knowledge www.clok.uclan.ac.uk 


\title{
Investigation of Polyviologens as Oxygen Indicators in Food Packaging
}

\author{
Luke Roberts $^{a, b}$, Robert Lines ${ }^{a}$, Sub Reddy ${ }^{b}$, John Hay ${ }^{b, *}$ \\ a SunChemical, Cray Avenue, St Mary Cray, Kent BR5 3PP, UK \\ b University of Surrey, Guildford, Surrey GU2 7XH, UK
}

\begin{abstract}
A triggered oxygen indicator, formulated from a combination of electrochrome, titanium dioxide and EDTA, was evaluated for use in food packaging. Methylene blue was not an ideal electrochrome due to its slow reduction to the leuco form and fast subsequent oxidation by oxygen present at low concentrations, $<0.5 \%$. Polyviologen electrochromes showed much faster reduction after exposure to UV light. Thionine and 2,2'-dicyano-1,1'dimethylviologen dimesylate, which have more anodic reduction potentials compared to methylene blue, can be used to produce oxygen indicators with decreased sensitivity to oxygen. These indicators can be used to detect oxygen even when levels increase up to $4.0 \%$.
\end{abstract}

\section{Introduction}

Food products are often packaged in modified atmosphere (MA) packaging, involving low oxygen concentration to limit oxidative spoilage of the product [1-3]. As low oxygen concentration MA is important for determining the shelf life of the product, a means of identifying the integrity of the MA is required. Oxygen indicators have been proposed to visually determine the integrity of the low oxygen concentration MA. Many oxygen indicator devices have been proposed for inclusion into food packaging [4-10], but limitations due to legislation, cost and reliability have restricted their commercial use [3, 11]. The simplest oxygen indicator system [4] uses a reducing agent to generate the colourless reduced species, methylene blue, which can then interact with oxygen present in the packaging to regenerate the original blue colour. The reduced form reacts with atmospheric oxygen immediately upon formation and therefore needs to be stored in an oxygen free environment before it is inserted into food packaging. A triggered system would circumvent the need to carefully store the reactive form prior to use. One example uses a semiconductor mediated UV reduction [10]. A printing ink with oxygen indicative properties has been 
suggested as a cheap method of producing an oxygen indicator suitable for food packaging $[3]$.

Unfortunately, the commonly used electrochromic dye, methylene blue, indicates the presence of oxygen at very low concentrations [3]. The redox potential of methylene blue, $\left(\mathrm{E}^{\circ} 11 \mathrm{mV}\right.$ vs. NHE) is significantly below the redox potential of oxygen [12-13], therefore the reduced form is highly reactive to oxygen. The oxygen indicator quickly becomes completely oxidised at concentrations below $0.5 \%$ oxygen. This sensitivity may be required for some food packages but there are applications where higher residual oxygen levels are acceptable and therefore these indicators would be too sensitive. Fruits and vegetables can be packed at low oxygen concentrations to reduce respiration and the associated production of ethylene. These processes result in depletion of the water and nutrients of the product leading to loss of product weight and a wilted or shrivelled unmarketable product. Examples of MAP fresh produce are avocados packed at 2-5\% oxygen and chilli peppers packed at $5 \%$ oxygen. In India, the world's largest fruit producer, $20-22 \%$ of fruit produce is lost due to post harvest spoilage [14]. There is also the concern that the oxygen indicators could alert the presence of oxygen prematurely which will deter customers from purchasing product that is still safe for consumption, thus increasing losses [11]. Furthermore, where an oxygen scavenger is incorporated into a package the amount of time required for the scavenger to remove residual oxygen could trigger the indicator prematurely.

Previous work with similar semiconductor mediated reduction of electrochromic dyes [15] has highlighted that an electrochrome with an anodic reduction potential such as dichloroindophenol, ( $\mathrm{E}^{\circ} 228 \mathrm{mV}$ vs. $\mathrm{NHE}$ ), produces a reduced species after exposure to $\mathrm{UV}$ light, which is stable in atmospheric oxygen of up to $21 \%$. This paper investigates the incorporation of electrochromes with redox potentials between methylene blue and dichloroindephonol to produce oxygen indicators which have a higher tolerance to oxygen above $0.5 \%$ but still react with oxygen to detect its presence above a set concentration more suitable to food packaging. For example, thionine is a commercially available electrochrome which has a redox potential of $62 \mathrm{mV}$ vs. NHE [12].

Viologens are also investigated in this paper. They are electrochromic compounds which are pale in the oxidised form and highly coloured in the reduced form [16]. Generally, viologens 
have highly anodic redox potentials, but viologens with more cathodic reduction potentials are also known, e.g. 2,2'-dicyano-1,1'-dimethylviologen dimesylate (90 mV vs. NHE) [17].

The viologens can be produced as polymers by condensation polymerisation of 4,4'bipyridine and an alkyl dihalide or ditosylate. Polyviologens retain the redox properties of the viologen parent compounds but are less susceptible to possible migration within food packaging [18-19].

\section{Material and methods}

Poly(butylviologen dibromide) and poly(p-xylylviologen dibromide) were synthesised as in [18-19], 2,2'-dicyano-1,1'-dimethylviologen dimesylate was synthesised as in [17]. Titanium dioxide was obtained from Degussa (P25 Aerosil). All other materials were obtained from Aldrich.

Oxygen indicators were produced using general formula set out by Mills and Lee [10]. These inks were then printed onto a polypropylene substrate by simple draw down printing using a K-bar.

\section{Methylene blue based oxygen indicator}

A $2 \%(\mathrm{w} / \mathrm{v})$ solution of methylene blue was prepared by dissolving methylene blue (1.03 $\mathrm{g})$ in deionised water and then making up to $50 \mathrm{ml}$. This solution $(0.25 \mathrm{~g})$ was then mixed with Degussa P25 titanium dioxide (0.25 g) and sodium EDTA (0.25 g) in 5\% (w/v) HEC solution $(10 \mathrm{ml})$. The ink was sonicated for 30 seconds. Isopropanol $(1 \mathrm{~g})$ was added to the solution immediately before printing.

\section{Thionine based oxygen indicator}

A $2 \%(\mathrm{w} / \mathrm{v})$ solution of thionine was prepared by dissolving thionine $(0.20 \mathrm{~g})$ in deionised water up to $10 \mathrm{ml}$. This solution $(0.26 \mathrm{~g})$ was then mixed with titanium dioxide $(0.25 \mathrm{~g})$ and sodium EDTA $(0.25 \mathrm{~g})$ in $5 \%(\mathrm{w} / \mathrm{v})$ HEC solution $(10 \mathrm{ml})$. The ink was sonicated for 30 seconds. Isopropanol $(1 \mathrm{~g})$ was added to the solution immediately before printing. 
2,2'-dicyano-1,1'-dimethyl-4,4'-dipyridinium dimesylate (0.25 g), Degussa P25 titanium dioxide $(0.25 \mathrm{~g})$ and sodium EDTA $(0.25 \mathrm{~g})$ were mixed into a 5\% (w/v) HEC aqueous solution (10 g). The solution was sonicated for 30 seconds. Isopropanol (1 g) was added immediately before printing.

\section{$\underline{\text { Poly(butylviologen dibromide)/EDTA/HEC }}$}

Degussa P25 titanium dioxide $(0.25 \mathrm{~g})$, sodium EDTA $(0.25 \mathrm{~g})$ and poly(butylviologen dibromide) $(0.25 \mathrm{~g})$ were dissolved in $5 \%(\mathrm{w} / \mathrm{v}) \mathrm{HEC}$ in deionised water $(10 \mathrm{ml})$. The solution was sonicated for 30 seconds. Isopropanol $(1 \mathrm{~g})$ was added immediately before printing.

\section{Poly(p-xylylviologen dibromide)/EDTA/HEC}

Degussa P25 titanium dioxide $(0.25 \mathrm{~g})$, sodium EDTA $(0.25 \mathrm{~g})$ and poly(p-xylylviologen dibromide) $(0.25 \mathrm{~g})$ were dissolved in $5 \%(\mathrm{w} / \mathrm{v})$ hydroxyethylcellulose (HEC) in deionised water $(10 \mathrm{ml})$. The sample was sonicated for 30 seconds. Isopropanol (1 g) was added immediately before printing.

As a method to analyse the oxygen indicator formulations at low oxygen concentrations, modified atmosphere (MA) pouches were produced. Pouches were prepared from laminates of polyethylene and Camclear plastic films. Polyethylene was used to enable heat-sealing of the pouches; Camclear gave the pouches a low oxygen transmission rate (OTR). The pouch was then MA packed using a Multivac instrument which firstly, evacuated the atmosphere to 1-5 mbar and secondly, admitted nitrogen to 750 mbar. The low OTR, of the Camclear layer, meant the pouches could be created oxygen free, and oxygen increased passively by migration through the Camclear laminate over a period of time. Using this method the performance of the indicators could be investigated in an environment as close to the final food MA packaging application as possible. Oxygen indicator films, made with different electrochromes, were printed using a No. 2 K-bar onto a white polypropylene film and MA packed within the pouches. Effectively, this gave some control over the concentration of oxygen the indicators were exposed to. Accurate oxygen concentrations were obtained using an Oxysense $\mathrm{TM}^{\mathrm{TM}}$ instrument and an Oxydot ${ }^{\mathrm{TM}}$ within the pouch. Oxysense ${ }^{\mathrm{TM}}$ measured fluorescence decay to accurately determine oxygen concentrations [20]. The oxygen indicators were then activated with UV light from a Natgraph UV rig, which used a medium pressure mercury arc lamp, and a conveyer speed of 20 metres per minute, which supplied 
$370 \mathrm{~mJ} \mathrm{~cm}{ }^{-3}$ energy. The major emission is at $365 \mathrm{~nm}$. The colour intensity of the indicators was monitored over a period of time by transmission reflectance measured using an Ocean optics UV-vis spectrometer between 400 and $900 \mathrm{~nm}$.

\section{Results and discussion}

\subsection{Reduction of polyviologen compared to methylene blue based indicators}

Poly(p-xylylviologen dibromide) was used to compare the effectiveness of the polyviologens with methylene blue. The samples were activated simultaneously using the Natgraph UV rig, and therefore show the same degree of UV exposure, seen in Figure 1. A dark purple colour was generated for the polyviologen based system, which lasted less than 30 seconds before bleaching back to the clear transparent film, suggestive of oxidation by air.

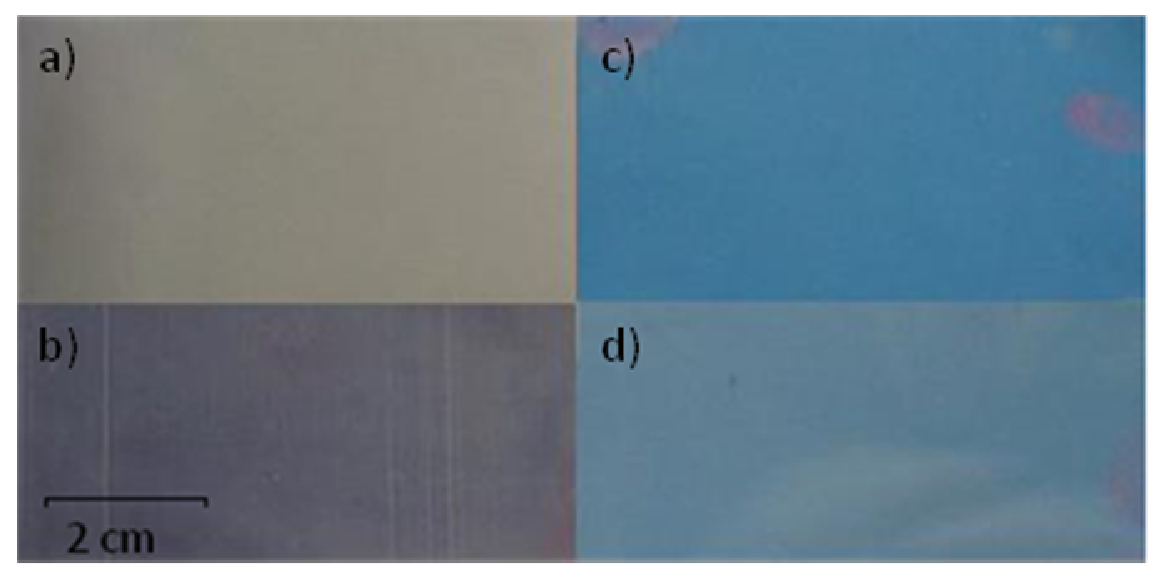

Figure 1: Comparison between methylene blue (c, d) and poly(p-xylylviologen dibromide) $(a, b)$ based oxygen indicators, before $(a, c)$ and immediately after $(b, d)$ exposure to UV light.

Although there is still a distinct colour change for the methylene blue system, the poly(pxylylviologen dibromide) based indicator was seen to reduce much more efficiently. The colour change, from pale yellow to dark purple for poly(p-xylylviologen dibromide), was also much more visually impressive than dark blue to pale blue for methylene blue. Compared to methylene blue, polyviologen based oxygen indicators required less UV irradiation to develop an intense colour change. Methylene blue based indicators required significantly 
more exposure to UV light, equal to 4 passes under the Natgraph UV rig to completely bleach the colour. As the films were open to air, the oxidation of the reduced electrochrome is occurring after UV activation, and a high rate of oxidation could be responsible for the limited colour change seen for methylene blue. However, comparison of the redox potentials for methylene blue (11 mV vs. NHE) and poly(p-xylylviologen dibromide) (-165 mV vs. NHE) suggests that the reduced species of the latter is more readily oxidised [12]. As a clear colour change can be seen for poly(p-xylylviologen dibromide), fast oxidation is unlikely to be the cause of limited reduction of methylene blue, as in Figure 1. The limited colour contrast of the methylene blue indicator is also a product of its strong coloured species being the oxidised form. In the methylene blue system, the indicator is blue when oxidised and a large proportion of the electrochrome needs to be reduced to the leuco form for the indicator to appear clear. This therefore requires extended UV exposure to mediate the reduction of large quantities of the electrochrome. The polyviologens on the other hand, are colourless in the oxidised form and any reduction of the electrochrome results in the generation of a distinct colour change. Only a small fraction of polyviologen needs to be reduced for a distinct colour change to occur. However, the more polyviologen reduced the more intense the colour change would be, and the more electrochrome in the reduced state available to react with oxygen.

Trials of the indicators based on poly(p-xylylviologen dibromide) and methylene blue showed that they are sensitive to very low oxygen concentrations and respond to the presence of oxygen at $0.5 \%$. These indicators are therefore unsuitable for applications where higher oxygen concentrations are tolerable or an oxygen scavenger is used.

\subsection{Sensitivity to oxygen}

To decrease the sensitivity of the oxygen indicator to oxygen, electrochromes with more anodic redox potentials were identified. The electrochromes thionine (62 mV vs. NHE) and 2,2'-dicyano-1,1'-dimethyl-4,4'-dipyridinium dimesylate (90 $\mathrm{mV}$ vs. NHE) were incorporated into oxygen indicator formulations and investigated for their sensitivity to oxygen. As a comparison, indicators produced with methylene blue and poly(butylviologen dibromide) were included. 
The transmission spectra of the oxygen indicators as the oxygen concentration was increased are seen in Figure 2(a-d). The initial reflectance transmission spectrum of the inks before activation was measured using an Ocean Optics device, and referred to as "ref" in the graphs. The indicators were then placed in a Camclear and polyethylene laminate pouch, with an OxyDot $^{\mathrm{TM}}$ indicator dot and then MA packaged to $0 \%$ oxygen. The indicators were activated using a Natgraph UV rig. To ensure no subsequent photoreduction occurred, the indicator was stored in a dark place and left for oxygen to gradually migrate into the package. The indicators were evaluated at oxygen concentrations of $0.00,1.16,2.45$ and $4.00 \%$, measured over a period of 5 days.

Methylene blue was seen to display the presence of oxygen at low oxygen concentrations, in this case, below 1.16\%, shown in the UV-vis spectra plotted in Figure 2(a). Also, the indicator based on poly(butylviologen dibromide) was also seen to detect oxygen at below $1.16 \%$ oxygen concentration, shown by UV-vis spectra in Figure 2(b). This is indicated by an increase in transmission as the reduced form of poly(butylviologen dibromide) is oxidised by oxygen back to its colourless form. This study investigated how the indicators interacted with oxygen at relatively higher oxygen concentrations and as such, the exact oxygen concentration at which either the methylene blue or poly(butylviologen dibromide) indicated the presence of oxygen was not determined. 


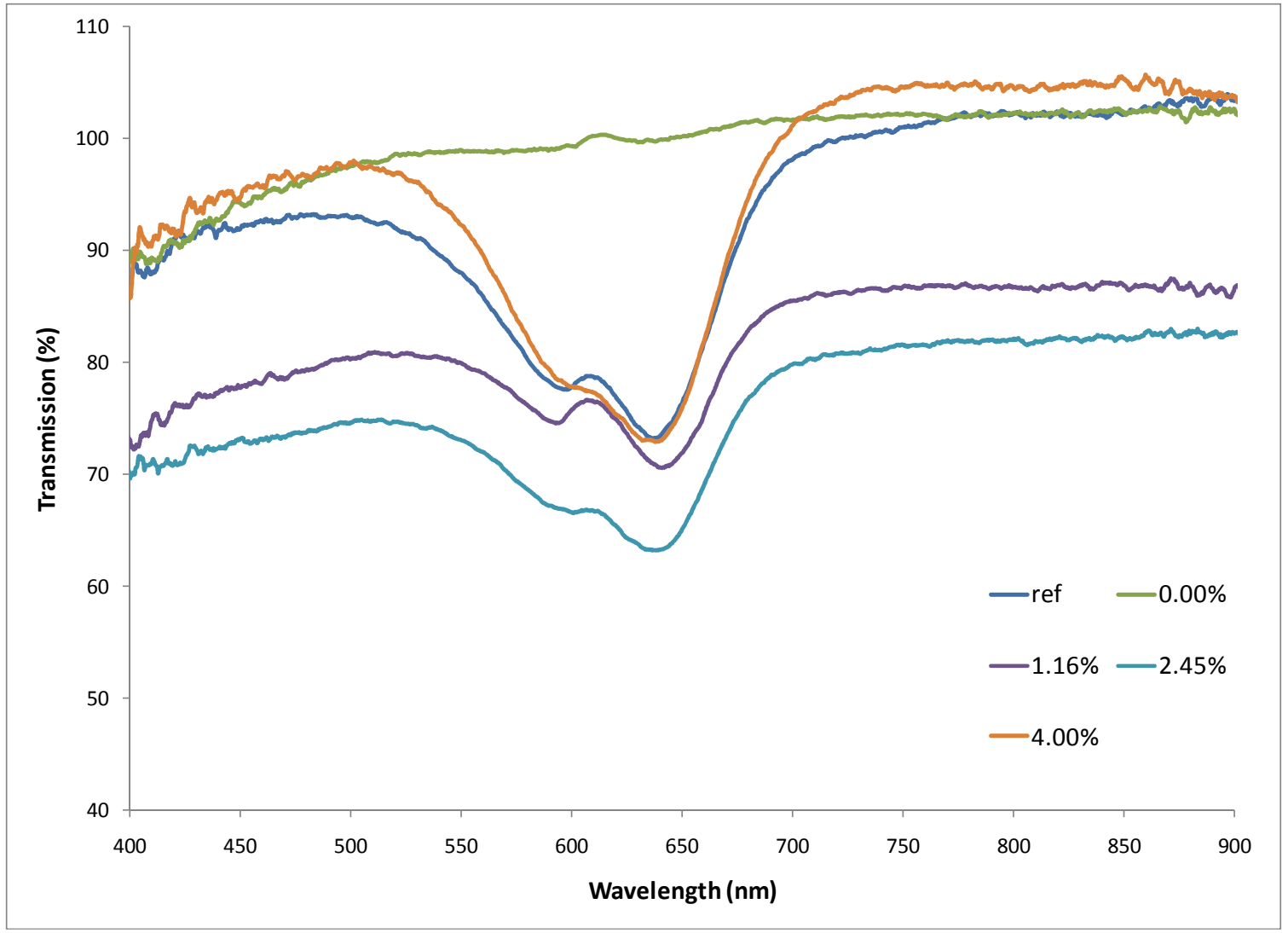

Figure 2 (a): UV-vis spectra of methylene blue ink formulation in MAP pouch over range of oxygen concentrations, from $0.00 \%$ to $4.00 \%$. 


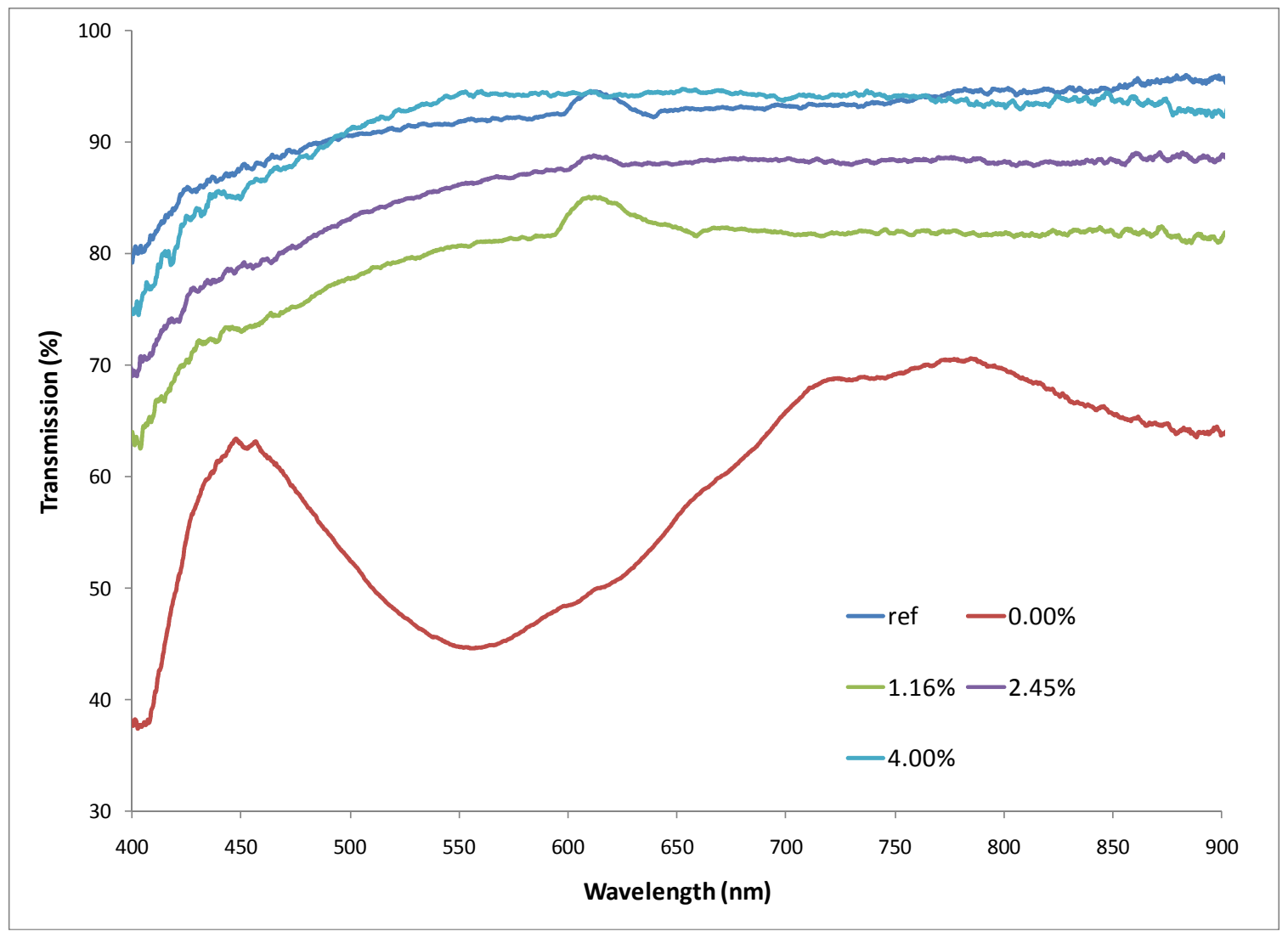

Figure 2(b): UV-vis spectra of poly(butylviologen dibromide) ink formulation in MAP pouch over range of oxygen concentrations, from $0.00 \%$ to $4.00 \%$.

With the thionine based indicator, the concentration of oxygen needed to be higher before the dye changed to the oxidised form. In this case, the reduced colourless state was still present at 1.16 and $2.45 \%$ oxygen as seen in the UV-vis spectra plotted in Figure 2 (c). The colour eventually returned by $4.00 \%$ oxygen. 


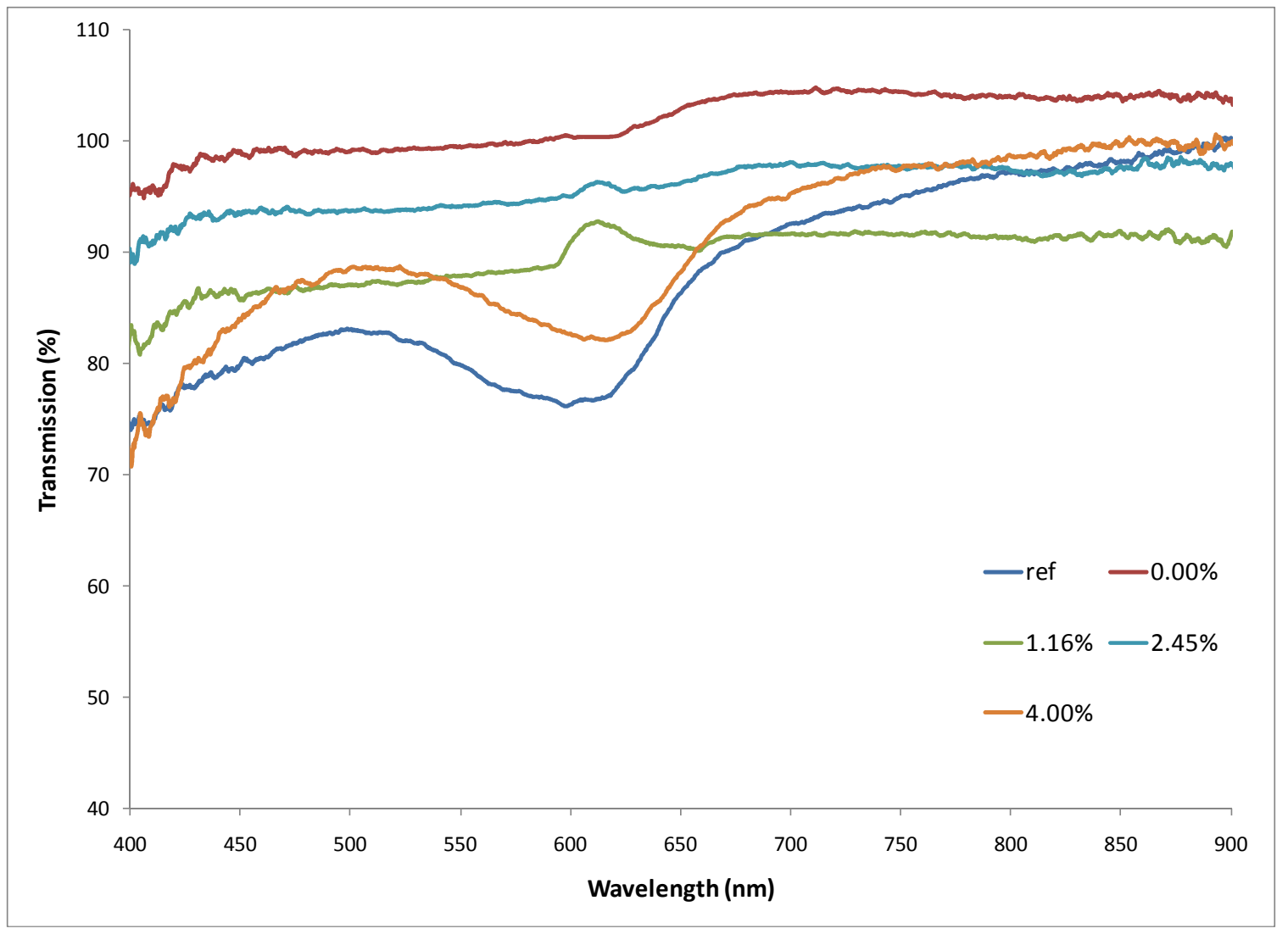

Figure 2 (c): UV-vis spectra of thionine ink formulation in MAP pouch over range of oxygen concentrations, from $0.00 \%$ to $4.00 \%$

The 2,2'-dicyano-1,1'-dimethyl-4,4'-dipyridinium dimesylate based ink showed an even higher tolerance to oxygen, as shown in Figure 2 (d). The coloured reduced state persisted at much higher oxygen concentrations, as can be seen by the low transmission compared to the reference. A strong colouration still remained at $4.00 \%$ oxygen within the MA pouch. Although there was a gradual increase in transmission, i.e. gradual oxidative bleaching, in the UV-vis spectra, even at $4.00 \%$ oxygen there was a clear visual difference from the reference, and therefore the electrochrome had not been completely oxidised. The experiment was terminated by rupturing the pouch, and the 2,2'-dicyano-1,1'-dimethyl-4, 4'-dipyridinium dimesylate oxygen indicator was seen to revert back to its original clear film within 30 minutes. 


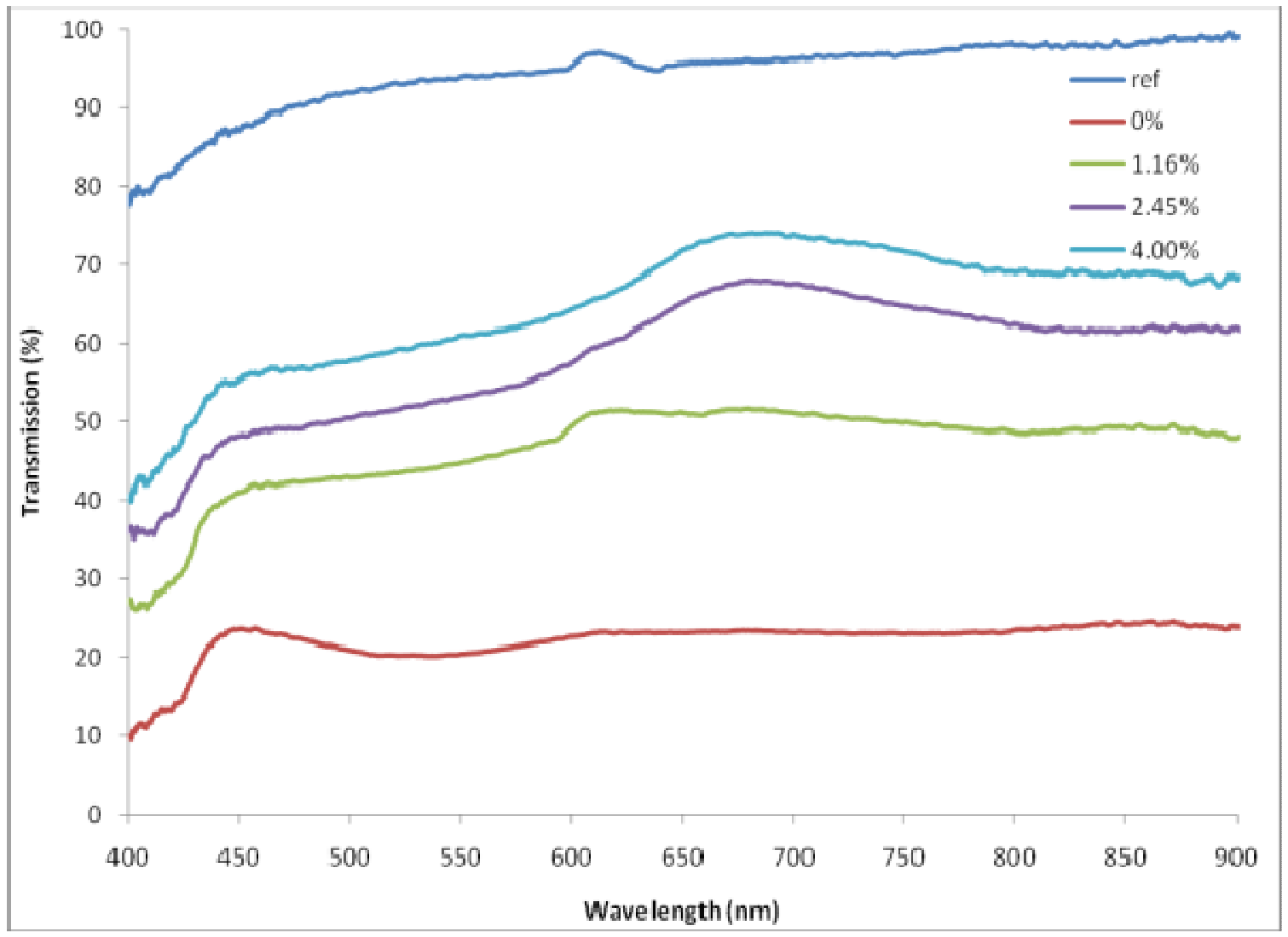

Figure 2 (d): UV-vis spectra of 2,2'-dicyano-1,1'-dimethyl-4,4'-dipyridinium dimesylate ink formulation in MAP pouch over range of oxygen concentrations, from $0.00 \%$ to $4.00 \%$.

Thionine showed a greater stability to oxygen compared to methylene blue and poly(butylviologen dibromide). 2,2'-dicyano-1,1'-dimethyl-4,4'-dipyridinium dimesylate showed the highest stability to oxidation, compared to all other electrochromes investigated. This is due to the anodic $\mathrm{E}^{\circ}$ redox potential for this viologen compound, $90 \mathrm{mV}$ [17], compared with poly(butylviologen dibromide), $-229 \mathrm{mV}$, methylene blue, $11 \mathrm{mV}$, and thionine, $63 \mathrm{mV}$ (vs. NHE) [12].

It can also be seen from the spectra of the 2,2'-dicyano-1,1'-dimethyl-4,4'-dipyridinium dimesylate indicator, in Figure 2 (d), that there is a possibility for this colorimetric indicator formulation to be used as a quantitative oxygen indicator, as there is a gradual increase in transmission with increasing oxygen concentration.

Other dyes could be used to fine tune an oxygen indicator with different oxygen concentration thresholds, so an indicator would be available for MA packaging with a variety 
of specific oxygen concentrations. Indicators with different oxygen thresholds could be incorporated together to produce a novel quasi-quantitative indicator, i.e. a methylene blue, thionine and 2,2'-dicyano-1,1'-dimethyl-4,4'-dipyridinium dimesylate combined indicator would show different colouration as the oxygen concentration increased from $0.0-4.0 \%$.

\section{Conclusions}

Electrochromic dyes can form reduced species that have a different colour to the oxidised form. The reduced species can react with molecular oxygen to regenerate the oxidised electrochromes and therefore can be useful as oxygen indicators. Different electrochromes were formulated into an oxygen indicator that was triggered by UV light by mediated reduction via EDTA and titanium dioxide. The oxygen indicator based on poly(pxylylviologen dibromide) was more efficient in the trigger step compared to methylene blue, determined by colour contrast after activation. This is because polyviologens are colourless in the oxidised state and deeply coloured in the reduced state. This facilitates the appearance of colour contrast during the reduction step as all the electrochrome in the system does not need to be reduced for a colour appearance to occur. For methylene blue a greater proportion of the dye needs to be reduced to achieve a perceivable colour change to the human eye. This is currently a problem for indicators based on methylene blue as the reduction process requires a long exposure time to UV light. Polyviologens, such as poly(p-xylylviologen dibromide), can therefore be used in the Strathclyde system when food products are sensitive to UV exposure associated with the photoreduction step.

As the oxygen indicator detects oxygen by the reduced electrochrome reacting with oxygen, the reactivity of the electrochrome to oxidation can be used as a means of controlling the sensitivity of the indicator to oxygen. Generally, the more cathodic the reduction potential of the electrochrome, the more reactive the reduced species is to oxidation. Conversely the more anodic the reduction potential of the electrochrome, the less reactive the reduced species will be to oxidation by molecular oxygen. As long as the redox potential of the electrochrome is more cathodic than the redox potential of oxygen this can be used to produce an oxygen indicator with a decreased sensitivity to oxygen. 
Two electrochromes were identified with relatively anodic redox potentials, thionine and the viologen 2,2'-dicyano-1,1'-dimethyl-4,4'-dipyridinium dimesylate. These electrochromes were incorporated into an oxygen indicator formulation [10] and their interaction with oxygen at low concentrations was analysed. The reduced form of thionine was seen to persist until the oxygen concentration exceeded $2.25 \%$ oxygen. The reduced form of 2,2'-dicyano1,1'-dimethyl-4,4'-dipyridinium dimesylate was seen to persist above $4.00 \%$ oxygen, but the intensity of the colour was seen to gradually decrease between 1.16 and $4.00 \%$. These indicator formulations could therefore be used to detect oxygen when concentrations above $0.5 \%$ are acceptable.

\section{References}

[1] A. L. Brody, B. Bugusu, J. H. Han, C. Koelsch Sand, and T. H. McHugh, Innovative food packaging solutions, J. Food. Sci., 73 (2008) 107 - 116.

[2] K. W. McMillin, Where is MAP Going? A review and future potential of modified atmosphere packaging for meat, Meat Sci., 80 (2008) 43 - 65.

[3] A. Mills, Oxygen indicators and intelligent inks for packaging food, Chem. Soc. Review, 34 (2005) $1003-1011$.

[4] Y. Yoshikawa, T. Nawata, M. Goto and Y. Fujii, Mitsubishi Gas Chemical Co., U.S. Pat 4,169,811 (Oct. 2 1979)

[5] H. Hatakeyama, S. Tobari, S. Iwauchi and M. Ohsawa, Mitsubishi Gas Co., U.S Pat 6,676,901 (Jan. 13, 2004)

[6] S. Piletsky, S. P. J. Higson and F. Davis, Cranfield University, Int. Pat. 06/024848 (Mar. $3,2006)$

[7] C. R. Barmore, D. V. Speer, T. D. Kennedy and M. R. Havens, Cryovac Inc., Int. Pat. 04/052644 (Jun. 24, 2004)

[8] D. L. Putnam and T. Hubbard, Photonic Systems, U.S. Pat. 6,794,191, (Sep. 21, 2004)

[9] E. W. Saaski, D. A. McCrae and D. M. Lawrence, MetriCor Inc., U.S. Pat. 5,039491, (Aug. 13, 1991)

[10] A. Mills and S. K. Lee, Strathclyde University, Int. Pat WO 03/021252 (2003)

[11] D. Dainelli, N. Gontard, D. Spyropoulos, E. Zondervan-van den Beuken and P. Tobback, Trends in Food Sci. Tech. 19 (2008) S103 - S112. 
[12] J. R. Norris and D. W. Ribbons, Methods in Microbiology, Vol. 2, Academic Press, London, 1970

[13] C. Harmann, A. Hamnett and W. Vielstich, Electrochemistry, Wiley, Weinheim, 2007.

[14] Sandhya, Modified atmosphere packaging of fresh produce: Current status and future needs, LWT - Food Sci. Tech., 43 (2010) 381 - 392.

[15] A. Mills and M. McGrady, A study of new photocatalyst indicator inks, J. Photochem. Photobio. A. Chem., 193 (2008) 228 - 236.

[16] P. M. S. Monk, The Viologens: Physicochemical Properties, Synthesis and Applications of the Salts of 4, 4'- bipyridine, John Wiley \& Sons, Chichester, England, 1998

[17] R. Fielden and L. A. Summer, 2,2'-dicyano-1,1'-dimethyl-4,4'-bipyridylium di-cation - viologen indicator with a high redox potential, Experientia, 30(8) (1974) 843 - 844.

[18] A. J. Factor and G. E. Heinsohn, General Electric Co. U.S. Pat 3,694,384 (Sept, 26, 1972)

[19] M. Simon, Polaroid Corporation, U.S Pat, 3,641,034 (Feb, 8, 1972)

[20] D. B. Papkovsky, N. Papkovskaia, A. Smyth, J. Kerry, and V. I Ogurtsov, Phosphorescent sensor approach for non-destructive measurement of oxygen in packaged foods: Optimisation of disposable oxygen sensors and their characterization over a wide temperature range Anal. Letts., 33(9), 1755 - 1777 (2000) 